\title{
Surgical Management of Paediatric Empyema: Open Thoracotomy versus Video-assisted Thoracic Surgery
}

\author{
Farhan Ahmad Majeed ${ }^{1}$, Sohail Saqib Chatha², Usama Zafar1, Umar Farooq Chatha3 ${ }^{3}$ Abdullah Zakaullah Chatha ${ }^{3}$ \\ and Zain Farooq ${ }^{2}$ \\ 'Department of Thoracic Surgery, Combined Military Hospital, Multan, Pakistan \\ ${ }^{2}$ Department of Thoracic Surgery, Combined Military Hospital, Rawalpindi, Pakistan \\ ${ }^{3}$ Department of General Surgery, Fauji Foundation Hospital, Rawalpindi, Pakistan
}

\begin{abstract}
Objective: To compare the effectiveness of open thoracotomy and video assisted thoracic surgery (VATS) for empyema thoracis in paediatric population.

Study Design: Observational study.

Place and duration of study: This observational study was conducted at Department of Thoracic Surgery, CMH, Lahore, from October 2013 to August 2018.

Methodology: Medical record of children up to the age of 14 years who were operated for empyema thoracis was reviewed. Patients were divided into two groups: Open thoracotomy, and VATS; and compared for etiology, preoperative treatment, grade of empyema, procedure performed; histopathology and complications, e.g. post-thoracotomy neuralgia, surgical site infection, recurrence over 6 months.

Results: A total of 61 paediatric patients were operated for empyema thoracis. Age ranged between 1 to 14 years (mean $=10.25$ \pm 3.30 years). Most common etiology of empyema was tuberculosis in $24(39.3 \%)$ cases, followed by pneumonia in 22 (36.1\%). Surgical treatment consisted of open thoracotomy in $40(65.5 \%)$ cases, while $21(34.5 \%)$ underwent VATS. Postoperative X-ray was satisfactory in $38(95 \%)$ cases undergoing open thoracotomy as compared to $21(100 \%)$ cases undergoing VATS ( $p=v a l u e ~ 0.29$ ). There was no recurrence in either of the two groups over a follow-up period of six months. Overall complication rate was $32.5 \%$ (13 cases) in cases undergoing open thoracotomy, while $33.3 \%$ ( 7 cases) in VATS group ( $p=$ value 0.95$)$. There was one $(2.5 \%)$ mortality in open thoracotomy group, while no death occurred in VATS group. Conclusion: Early surgical treatment, both open as well as VATS, gives satisfactory results in management of paediatric empyema. VATS is a safe alternative to open thoractomy with good success rate and less incidence of complications.
\end{abstract}

Key Words: Empyema thoracis, Thoracotomy, VATS, Paediatrics.

How to cite this article: Majeed FA, Chatha SS, Zafar U, Chatha UF, Chatha AZ, Farooq Z. Surgical management of paediatric empyema: open thoracotomy versus video-assisted thoracic surgery. J Coll Physicians Surg Pak 2020; 30(3):309-312.

\section{INTRODUCTION}

Paediatric empyema thoracis is a common condition in children managed by thoracic and paediatric surgeons in developing countries, and is associated with significant morbidity and mortality. ${ }^{1}$ It is considered as a significant cause of paediatric hospital admissions, and especially in developing countries where hospital resources are limited.2 Most cases respond to antibiotic therapy and intercostals drainage in earlier stages; however, in majority of cases surgical management is required especially in our part of the world due to delayed presentations, multiresistant strains, delayed diagnosis, poor compliance with medication, and mismanagement at early stages of the disease. A meta-analysis performed

Correspondence to: Dr. Sohail Saqib Chatha, PAF Hospital, Lahore, Pakistan

E-mail:drsohailchatha@hotmail.com

Received: April 26, 2019; Revised: August 02, 2019;

Accepted: September 11, 2019 regarding management of paediatric empyema thoracis has shown that primary operative therapy is associated with lesser mortality, decreased hospital stay, shorter duration of antibiotic therapy and less chances of reintervention. ${ }^{3}$

Historically, the treatment consisted of open thoracotomy and decortications. However, now VATS is also being employed as a standard treatment at majority of centres by thoracic surgeons. Recent studies demonstrate the efficacy and safety of VATS in the treatment of empyema in children. 4,5

The purpose of this study was to evaluate and compare open thoracotomy and VATS in the management of paediatric empyema.

\section{METHODOLOGY}

This observational study was conducted in the Department of Thoracic Surgery, CMH, Lahore, from October 2013 to August 2018. Medical record of children with diagnosis of empyema thoracis from age 1 to 14 years, who had open thoracotomy or VATS, were 
reviewed retrospectively. The children included in the study were diagnosed with empyema thoracis based on purulent pleural tap and effusion demonstrated on chest X-ray, ultrasound, and CT scan of chest. Decision to perform open surgery or VATS was made by consultant thoracic surgeon based on condition of the patient and stage of the empyema. Stage 1 and early stage 2 empyema underwent VATS; whereas, late stage 2 and stage 3 empyemas were treated by open thoracotomy. All the procedures were performed by single surgeon. Fluid obtained was subjected to gross examination (total and differential cell count), biochemistry (sugar and protein), gram/AFB stain, and bacterial culture and sensitivity (C/S). The criteria for discharge of the patients were absence of fever for at least 3 days, expanded lung on postoperative chest X-ray, chest tube removed, absence of tachypnoea, and good oral intake. Patients were followed up for at least 6 months after discharge.

Data was analysed using SPSS statistical package 20.0. Descriptive statistics was used and analysed by using cross tabs; and level of significance was calculated using Pearson Chi-square test. P-value $<.05$ was considered significant.

\section{RESULTS}

Sixty-one children were treated surgically for empyema thoracis. Age ranged between 1 to 14 (mean $=10.25$ \pm 3.30 ) years. Tuberculosis was etiology in 24 (39.3\%) cases followed by pneumonia in $22(36.1 \%)$, other causes included trauma in $9(14.8 \%)$ cases, postsurgical in $3(4.9 \%)$ cases and $3(4.9 \%)$ cases had other causes. Organism isolated on $\mathrm{C} / \mathrm{S}$ were gram-negative in $17(27.9 \%)$ followed by gram-positive in $16(26.2 \%)$ cases and anaerobes in $6(9.8 \%)$ cases, while in 22 $(36.1 \%)$ no organism was isolated. There was no growth of AFB in any of the fluid sampes (Table I).

Treatment consisted of open thoracotomy in 40 (65.5\%) cases, while 21 (34.5\%) underwent VATS. In open procedure, standard posterolateral serratus sparing thoracotomy was done while in VATS uniportal incision was used. Average scar size in case of open thoracotomy was $11 \mathrm{~cm}$; whereas, in case of VATS it was $3 \mathrm{~cm}$ uniportal incision. Postoperative X-ray was satisfactory (expanded lung) in $38(95 \%)$ cases undergoing open thoracotomy as compared to $21(100 \%)$ cases undergoing VATS $(p=0.29)$. There was no recurrence in either of the two groups over a follow-up period of six months (Figure 1).

Overall complication rate was $32.5 \%$ (13 cases) in cases undergoing open thoracotomy, while $33.3 \%$ (7 cases ) in VATS group $(p=0.95)$. Most common complication in open thoracotomy group was PTN, which occurred in 9 $(22.5 \%)$ cases; while in VATS group, most common complication was again PTN but it occurred in $3(14.5 \%)$ cases $(p=0.44)$. There was $1(2.5 \%)$ mortality in open thoracotomy group while no death occurred in VATS group. Bleeding occurred in $5(12.5 \%)$ cases in open thoracotomy group, while in VATS group it occurred in $2(9.5 \%)$ cases. Surgical site infection occurred in $7(17.5 \%)$ cases in post-thoracotomy group, while no case of SSI occurred in those undergoing VATS $(p=0.042$, Figure 2).

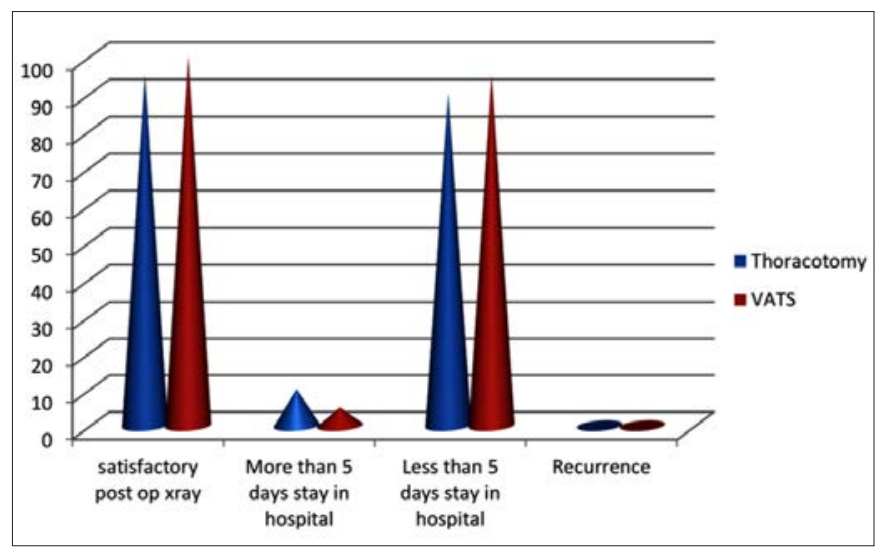

Figure 1: Postoperative efficacy of the two procedures.

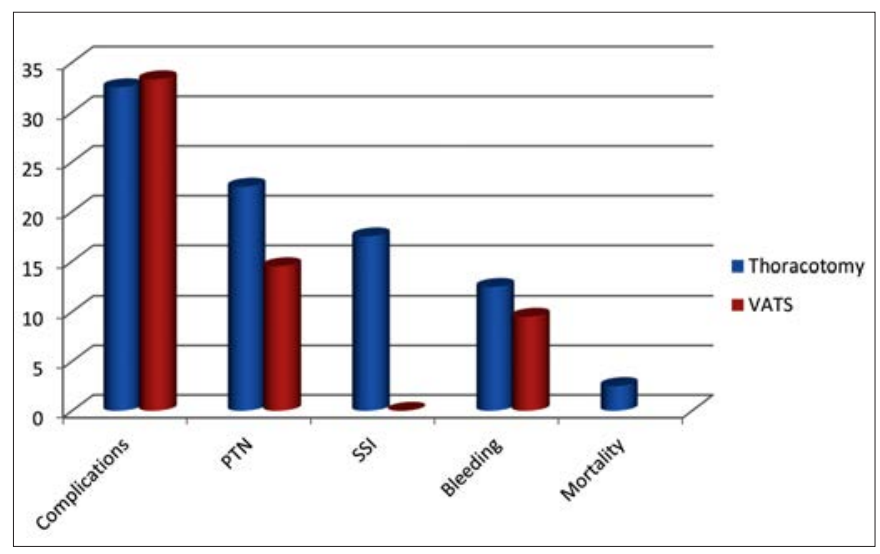

Figure 2: Complications of thoracotomy and VATS.

Table I: Baseline characteristics.

\begin{tabular}{lcc}
\hline Variable & Frequency & Percent \\
\hline Gender & 35 & 57.4 \\
Male & 26 & 42.6 \\
Female & & \\
\hline Grade of empyema & 16 & 26.2 \\
Early & 45 & 73.8 \\
Late & & \\
\hline Etiology & 24 & 39.3 \\
Tuberculosis & 22 & 36.1 \\
Pneumonia & 9 & 14.8 \\
Post-trauma & 3 & 4.9 \\
Post-surgical & 3 & 4.9 \\
Others & & \\
\hline Organism on C/S & 22 & 36.1 \\
Nil & 17 & 27.9 \\
Gram negative & 16 & 26.2 \\
Gram positive & 6 & 9.8 \\
Anaerobes & & \\
\hline
\end{tabular}


Overall hospital stay was less than 5 days in $36(90.0 \%)$ cases in open thoracotomy group, while $20(95 \%)$ patients stayed less than 5 days in VATS group $(p=0.48)$. In open thoracotomy group, single chest tube was inserted in $23(57.5 \%)$ cases, while 2 chest tubes were inserted in $17(42.5 \%)$ cases whereas in VATS group single chest tube was inserted in $20(95 \%)$ cases while in only $1(5 \%)$ case 2 chest tubes were inserted. Average day of chest tube removal for first chest tube was 2.8 days in VATS group, while in thoracotomy group first chest tube was removed averagely on 2.3 days, while second chest tube was removed averagely on 5.4 days. Blood transfusion was needed in $19(47.5 \%)$ cases in open thoracotomy group while in VATS group blood transfusion was needed in 7 (33\%) cases.

\section{DISCUSSION}

Early aim in the management of empyema is to control sepsis and eradicate the fever by evacuation and sterilisation of pleural cavity and ensuring reexpansion of the lung and restoration of lung function; 6 whereas, the long term aim is to prevent lung damage. Inadequate treatment and drainage can lead to persistence of infection and significant morbidity and mortality. Early and prompt surgical treatment is necessary to achieve this goal. However, decision to choose between operative and non-operative treatments has been a matter of debate amongst clinicians treating empyema thoracis due to difficulty in adequately deciding the stage of empyema. ${ }^{7}$ However, it has been shown in multiple studies that earlier intervention and debridement yields better results. ${ }^{8,9}$ The indication and choice of surgical intervention depend largely on stage of the disease, local surgical experience and expertise and personal preference of the surgeon. With growing trend towards non-invasive surgery, thoracoscopy has established its place in the management of thoracic empyema even in paediatric population. With the advent of fibreoptic and more advanced instrumentation, more thoracoscopic procedures are now being performed. ${ }^{10,11}$

This study highlighted the effectiveness of early surgical treatment for empyema thoracis in children and effectiveness of VATS, especially in early stages of empyema.

The use of VATS in the management of fibrinopurulent stage 2 empyema has shown rewarding results in several reports. 12,13 It was shown in the present study as well, where $75 \%$ of empyema was of late stage and effectively treated by VATS. In one of the largest studies, which was conducted in the United Kingdom by Bishay et al.,14 114 children underwent and it was concluded that VATS has a very good outcome in childhood empyema as it has an important role in the management of this condition. This finding was verified in this study as well, where $100 \%$ X-rays in the postoperative period showed fully expanded lungs and resolution of empyema. There was no recurrence over a follow-up period of six months. In one of the retrospective studies conducted on VATS for management of paediatric empyema, there was good pleural recovery and zero mortality, 15 and these findings are consistent with the results of this study.

In this study, mean hospital stay was less than 5 days in 90 percent of patients undergoing open thoracotomy and $95 \%$ of patients undergoing VATS. In the study conducted by Jadhav et al.,16 the median postoperative hospital stay was $10.31 \pm 3.751$ days in case of VATS, whereas in case of open thoracotomy it was $4.41 \pm 1.593$ days. Gupta et al. 17 found a more rapid recovery with a less number of chest tube days and decreased length of hospital stay. In the present study, the average time of chest tube removal was 2.8 days while in thoracotomy it was 5.4 days. In a study conducted by Sharma et al, chest tube was removed on an average 7 days in VATS arm, while in a primary thoracotomy arm longer time (16 days) required for chest tube removal. ${ }^{18}$

Use of VATS in the management of empyema thoracis in children has gained popularity in last few years. VATS is suggested to have potential advantages over open surgery in terms of having shorter incisions and lesser injury to muscles, nerves and lesser incidence of post operative pain, infection and scar size. ${ }^{19}$ This study also verified this fact where PTN was less in case of VATS $(14.5 \%$ vs. $22.5 \%)$, no case of surgical site infection (SSI) vs. $17.5 \%$ in open thoracotomy. In this study, success rate in the treatment of empyema was similar in both groups (VATS vs Open thoracotomy) and this fact has been verified in various studies.

Retrospective collection of data and smaller number of cases are major limitations of this study. However, this study gives an insight into the management of paediatric empyema, based on which well designed studies can be conducted to establish standard guidelines.

\section{CONCLUSION}

In the present study, early surgical treatment, whether open or VATS, gives satisfactory results in the management of paediatric empyema; and VATS is an attractive and safe alternative to open thoracotomy in experienced hands with equal success rate and lesser incidence of complications and postoperative morbidity and mortality. Moreover, similar results have been reported in the literature as well.

\section{ETHICAL APPROVAL:}

Institutional and Ethical Review Commitee of CIMS approved the study and the said letter was sent as well.

\section{PATIENTS' CONSENT:}

Consent was obtained from patients regarding publication of data 


\section{CONFLICT OF INTEREST:}

Authors declared no conflict of interest.

\section{AUTHORS' CONTRIBUTION:}

FAM, SSC, UZ, UFC, AC, ZF: Data collection, literature review, and analysis.

\section{REFERENCES}

1. Menon P, Kanojia RP, Rao KLN. Empyema thoracis: Surgical management in children. Int J Contemp Pediatr 2017; 4:882-5.

2. Mishra OP, Das BK, Jain AK, Lahiri TK, Sen PC, Bhargara V. Clinico-bacteriological study of empyema thoracis in children. J Trop Pediatr 1993; 39:380-1.

3. Avansino JR, Goldman B, Sawin RS, Flum DR. Primary operative versus nonoperative therapy for pediatric empyema: A meta-analysis. Pediatrics 2005; 115:1652-9.

4. Stringel G, Hartman AR, Marandi P. Video-assisted thoracoscopy for pulmonary decortication in children. Pediatr Surg Int 1995; 10:205-6.

5. Stovroff M, Teague G, Heiss KF, Parker P, Ricketts RR. Thoracoscopy in the management of pediatric empyema. $J$ Pediatr Surg 1995; 30:1211-5.

6. Avansino JR, Goldman B, Sawin RS, Flum DR. Primary operative versus nonoperative therapy for pediatric empyema: A meta-analysis. Pediatrics 2005; 115:1652-9.

7. Zampoli M, Zar HJ. Empyema and parapneumonic effusions in children: An update. SA J Child Health 2007; 1:121-8

8. Menon P, Kanojia RP, Rao KL. Empyema thoracis: Surgical management in children. J Indian Assoc Pediatr Surg 2009; 14:85-93

9. Kang DW, Campos JR, Andrade Filho Lde O, Engel FC, Xavier AM, Macedo $\mathrm{M}$, et al. Thoracoscopy in the treatment of pleural empyema in pediatric patients. J Bras Pneumol 2008; 34:205-11.
10. Yim AP, Hui-Ping L. Complications and failures of video-assisted thoracic surgery: Experience from two centers in Asia. Ann Thorac Surg 1996; 61:538-41.

11. Rodgers BM. Pediatric thoracoscopy: Where have we come and what have we learned? Ann Thorac Surg 1993; 56:704-7.

12. Ris HB, Krueger T. Video-assisted thoracoscopic surgery and open decortication for pleural empyema. Multimedia Manual Cardiothoracic Surg 2004; 000273.

13. Waller DA, Rengarajan A. Thoracoscopic decortication: A role for video-assisted surgery in chronic postpneumonic pleural empyema. Ann Thorac Surg 2001; 71:1813-16.

14. Bishay M, Short M, Shah K, Nagraj S, Arul S, Parikh D, et al. Efficacy of video-assisted thoracoscopic surgery in managing childhood empyema: A large single-centre study. J Pediatr Surg 2009; 44:337-42.

15. Manasa G. Paediatric empyema: Video-assisted thoracoscopic surgery (vats) and its outcome study. Int $J$ Contemp Pediatr 2017; 4:882-5.

16. Jadhav P. Surgical strategy of empyema thoracis in children: Open thoracotomy $\mathrm{V} / \mathrm{s}$ video assisted thoracoscopy. Int Surg $J$ 2018; 5:3823-5.

17. Gupta AK, Lahoti BK, Singh S, Mathur RK, Mishra H, Wadhera S. A study on comprehensive management of acute and chronic empyema thoracis in the pediatric age group and their outcome. Internet J Surg 2008; 14:1.

18. Sharma S, Sonker SK, Nirala S. Prospective comparative study of video assisted thoracoscopic surgery versus conventional thoracostomy drainage in emyema thoracis in paediatric age group. Int J Res Med Sci 2015; 3:2538-42.

19. Cardillo G, Carleo F, Carbone L, Martino MD, Salvadori L, Petrella L, et al. Chronic postpneumonic pleural empyema: comparative merits of thoracoscopic versus open decortication. Eur J Cardiothorac Surg 2009; 36:914-8. 